Disponível em:

http://editora.unoesc.edu.br/index.php/race

RACE, Joaçaba, v. 16, n. 1, p. 203-226, jan./abr. 2017

\title{
O PROCESSO DE SUCESSÃO EM DIFERENTES COMBINAÇÕES DE GÊNERO: UM ESTUDO COMPARATIVO DE CASOS EM EMPRESAS FAMILIARES DE MONTE CARMELO, MG
}

Succession process with different gender combination: a comparative study in family businesses in Monte Carmelo City, MG

\section{Andrea Costa van Herk Vasconcelos}

E-mail: andreaherk@ufu.br

Mestre em Administração pela Universidade Federal de Uberlândia; Pós-graduada (MBA) em Gestão Empresarial pela Fundação Getúlio Vargas do Rio de Janeiro; Pós-graduada em Administração de RH pelo Centro Universitário Una; Professora na Faculdade de Gestão e Negócios da Universidade Federal de Uberlândia.

Márcia Freire de Oliveira

E-mail: marciafreire@ufu.br

Pós-doutora em Administração pela Universidade de São Paulo de Ribeirão Preto; Doutora em Engenharia de Produção pela Universidade Federal de São Carlos; Professora da Faculdade de Gestão e Negócios da Universidade Federal de Uberlândia. Endereço para contato: Avenida João Naves de Ávila, 2121, Bloco 1F, Campus Santa Mônica, 38400-902, Uberlândia, Minas Gerais, Brasil.

Vivian Duarte Couto Fernandes E-mail: vivian@ufu.br

Mestre em Administração pela Universidade Federal de Uberlândia; Pós-graduada (MBA) em Gestão Empresarial pela Fundação Getúlio Vargas; Professora na área de Gestão de Pessoas da Universidade Federal de Uberlândia.

Artigo recebido em 31 de agosto de 2016. Aceito em 24 de setembro de 2016. 
Resumo

Neste artigo teve-se como objetivo analisar os desafios enfrentados por sucessores no processo de sucessão em empresas familiares, considerando diferentes combinações de gênero. A pesquisa é aplicada, qualitativa e exploratória, sendo um estudo comparativo de casos. Os dados foram coletados por meio de entrevistas em profundidade, estruturadas, em seis empresas da Cidade de Monte Carmelo, MG, e utilizou-se de análise de conteúdo para o tratamento dos dados. Os resultados apontam que nas combinações sucessor/sucedido (pai/filho - pai/filha - mãe/filho mãe/filha), alguns pontos são comuns: conflitos entre os membros, falta de planejamento, ideias de impotência por parte dos sucedidos e, em contrapartida, muito gosto pelos negócios. Na gestão conjunta (sucedido/sucessor), os conflitos são contundentes em que o sucedido é do sexo masculino (pai/filho e pai/filha). Na efetivação do processo sucessório, as mulheres/irmãs são colocadas à parte quando os sucedidos/sucessores são do sexo masculino (pai/filho) e vice-versa, os homens/irmãos são colocados à parte quando da combinação mãe/filha. Por fim, sucessores homens não necessitam provar suas capacidades perante os sucedidos/sucedidas (pai/filho e mãe/ filho), enquanto para as sucessoras essa é uma questão essencial (pai/filha e mãe/filha).

Palavras-chave: Empresas familiares. Processo sucessório. Gênero.

\section{Abstract}

In this article, the objective was to analyze the challenges faced by successors in the succession process in family businesses, considering different gender combinations. The research is applied, qualitative and exploratory, being a comparative case study. Data were collected through in-depth structured interviews at six companies in Monte Carmelo City, MG, and content analysis was used for the data treatment. The results show that in the successor/successed combinations (father/son - father/daughter - mother/son - mother/daughter), there are similarities: conflicts among members, lack of planning, disability feeling on successors despite the business passion. In joint management (sucessed/successor), there are hard conflicts when the sucessed is male (father/son and father/daughter). In effecting the succession process, women/sisters are set apart when sucessed/successors are male (father/son) and vice versa, men/brothers are set apart when there is a mother/daughter combination. Finally, male successors do not need to prove their abilities to succeed (father/son and mother/son), but in women successors this is an essential issue (father/daughter and mother/daughter).

Keywords: Family businesses. Succession process. Gender.

\section{INTRODUÇÃO}

As empresas familiares são reconhecidas por sua relevância econômica e social em todo o mundo. No Brasil, as empresas familiares representam cerca de 90\% das empresas não estatais e têm grande importância na absorção de mão de obra, geração de emprego e renda e aquecimento do mercado (MACEDO et al., 2004). 
O interesse pelo estudo em empresas familiares tem sido crescente nas pesquisas acadêmicas. Segundo Davel e Colbari (2000), as pesquisas em empresas familiares são realizadas sob duas dimensões: materiais e imateriais. As primeiras, foco deste estudo, têm caráter mais pragmático e funcionalista e abordam questões como: sucessão, ciclo de vida, profissionalização, estratégia, etc. E as segundas focam as questões simbólicas e culturais da organização, relacionando-as à imagem do universo familiar.

De forma complementar, o preparo de sucessores, que em geral era centrado na relação de pais e filhos, hoje tem como possibilidades múltiplas combinações de gênero, envolvendo: mãe e filha(s), mãe e filho(s), pai e filho(s) e pai e filha(s). Considerando as diferentes naturezas desses relacionamentos, esses aspectos devem ser incluídos nas pesquisas, a fim de melhor compreender as empresas familiares (GOFFEE, 1996 apud MACHADO, 2003).

Dessa forma, busca-se responder à seguinte questão: como os sucessores enfrentam os desafios do processo de sucessão, considerando diferentes combinações de gênero? Para responder a tal questão, o objetivo com este trabalho foi analisar os desafios enfrentados por sucessores no processo de sucessão em empresas familiares, observando diferentes combinações de gênero.

No estudo não se pretende esgotar as discussões sobre o tema, todavia, tem-se o intuito de oferecer reflexões que contribuam com a ampliação da visão, tanto teórica quanto analítica, sobre o processo de sucessão nas empresas familiares, bem como localizar as questões de gênero nesse contexto.

Além desta introdução, o trabalho é composto pelas seguintes partes: referencial teórico, que aborda as empresas familiares, o processo sucessório e a questão do gênero no processo sucessório; metodologia; análise dos resultados; e considerações finais.

\section{REFERENCIAL TEÓRICO}

\subsection{EMPRESAS FAMILIARES}

Donneley (1967) e Grzybovski e Tedesco (1998) consideram que para uma empresa ser familiar é preciso estar ligada a uma família pelo menos durante duas gerações, visto que essa ligação resulta em uma influência recíproca. Lodi (1998), seguindo a mesma perspectiva, coloca que o nascimento da empresa familiar ocorre, geralmente, com a segunda geração de dirigentes, uma vez que enquanto a empresa está nas mãos do fundador é apenas um negócio pessoal. Quaisquer que sejam as de- 
finições para um empreendimento familiar, todas ressaltam o desejo por uma intenção transgeracional. Esse desejo pode nascer com a organização ou ser desenvolvido ao longo da sua trajetória (WRIGHT; KELLERMANNS, 2011).

Considera-se, para fins específicos deste trabalho, que a empresa familiar é aquela com uma unidade econômica de produção, cuja função é a criação de riquezas mediante a produção de bens e serviços, sob a direção, responsabilidade e controle do empresário que a criou, assumindo a propriedade dela, em seu nome ou em representação de um consenso familiar. Essa concepção foi desenvolvida por Albi (1994 apud CONSOLI; MARTINELLI, 1998).

As empresas familiares são únicas porque a voz mais importante na empresa pertence, muitas vezes, a um grupo de pessoas ligadas por laços sanguíneos ou matrimoniais, e, assim, o poder na família, as instituições de governança familiar, a interação entre os membros da família e outros stakeholders, assim como a dinâmica familiar são provavelmente o que determinará os resultados da empresa (CATER III; KIDWELL; CAMP, 2016).

Vozikis, Weaver e Gibson (2009) elencam benefícios de uma empresa familiar: trabalhar com pessoas próximas, flexibilidade e segurança, construção de um legado financeiro para a aposentadoria e as gerações futuras. Por outro lado, seus desafios e aspectos englobam: personalidades conflitantes, falta de objetivos partilhados, falha de liderança, participação da família nos negócios, liderança e participação na preparação da próxima geração que assumirá a responsabilidade para o negócio, afastamento do fundador dos negócios da família, escolha dos sucessores e como escolher entre vários sucessores.

As particularidades existentes no processo de gestão das empresas familiares caracterizam-se pelas interferências que as representações da família têm sob as práticas de gestão, da mesma forma com que a história da organização se confunde com a história da família (DAVEL; COLBARI, 2003).

Entre as fases do ciclo de vida da empresa familiar, o processo de sucessão é considerado a fase mais crítica. É ainda nesse período que mais mortes de empresas familiares ocorrem principalmente por causa dos conflitos no seio da família (VOZIKIS; WEAVER; GIBSON, 2009).

\subsection{PROCESSO SUCESSÓRIO}

O processo sucessório é um momento bastante particular na existência das empresas familiares, caracterizado pela transferência de poder na empresa entre uma geração da família e outra (GERSICK et al., 1997). É um dos temas mais pesquisados 
sobre empresa familiar, talvez pela impressionante taxa de insucesso que as pesquisas apresentam: apenas 30\% das empresas familiares sobrevivem à segunda geração e 10 a 15\% sobrevivem à terceira geração (STAMM; LUBINSKI, 2011).

O processo de sucessão é composto por três etapas. A primeira envolve as atividades ligadas à preparação do sucessor; a segunda relaciona-se à escolha do sucessor, e a terceira refere-se ao momento em que o antecessor toma a decisão de sair da empresa e transfere a direção da organização ao sucessor (ST-CYR; RICHER, 2005).

A sucessão envolve uma série de dificuldades e desafios, visto que seu processo pode ser permeado por conflitos oriundos de fontes como: ausência de planejamento prévio, incerteza dos stakeholders (acionistas, fundador, membros da família, gestores, fornecedores, e clientes) quanto às possíveis alterações que podem ocorrer com a mudança no poder e na autoridade (VOZIKIS; WEAVER; GIBSON, 2009) e, também, segundo Scheffer (1995), a resistência do fundador em deixar a empresa.

Para que a sucessão intrafamiliar seja bem-sucedida, é preciso que os membros da próxima geração tenham a intenção de assumir a empresa e que os sucedidos que são os atuais gestores da organização - tenham a intenção de transferir a liderança do negócio para a próxima geração (MASSIS et al., 2016).

Flores Junior e Grisci (2012) buscaram destacar e analisar a vivência de dilemas no que se refere ao processo sucessório em empresas familiares. Para os autores, os dilemas enfrentados pelos pais/sucedidos estão relacionados à dualidade vida-morte (luta do sucedido pela sobrevivência, horror da expiração, medo de exclusão e pavor de morrer). Já os dilemas enfrentados pelos filhos/sucessores estão centrados na questão de legitimação pessoal (aprovação e valorização por parte dos pais/sucedidos e dos demais stakeholders da empresa).

Lodi (1987), de forma complementar, enfatiza três tipos de crise que costumam ocorrer no processo sucessório:

a) quando da passagem do bastão do fundador para o seu sucessor, pelo fato de o primeiro ser autocrata, centralizador, criar obstáculos à profissionalização e ter dificuldades em treinar e avaliar os filhos (LODI, 1987; CATER III; KIDWELL, 2013);

b) quando da passagem da segunda para a terceira geração, apontando para a necessidade de profissionalização;

c) quando da perda da identidade da empresa em relação aos seus objetivos. Essa crise coincide com interesses diferentes dos valores do fundador. 
Assim, argumenta-se que ter valores claros é uma das fontes de sucesso e sustentabilidade dos negócios familiares, bem como a existência de valores é um elemento-chave na gestão (SIMON et al., 2012).

De acordo com Vozikis, Weaver e Gibson (2009), duas dimensões caracterizam uma sucessão bem-sucedida: a satisfação das partes envolvidas no processo e a eficácia do processo, que está ligada ao impacto do processo sobre o desempenho da empresa familiar. Portanto, é possível inferir que existem vários fatores relacionados ao processo de sucessão das empresas familiares. Esses fatores variam desde questões acerca da herança, do ponto de vista financeiro, até as motivações familiares baseadas nas emoções e nos valores da família (HABERMAN; DANES, 2007; SILVA et al., 2013), assim como a questão do gênero (OVERBEKE; BILIMORIA; PERELLI, 2013).

Acredita-se que os atributos mais importantes para os sucessores são a integridade e o comprometimento com o negócio da família. Esse comprometimento é adquirido por meio de quatro bases:

a) afetiva, destacada pelo desejo percebido;

b) normativa, identificada no senso de obrigação;

c) calculista, quando se identifica o custo de oportunidade;

d) imperativa, quando há uma necessidade percebida (CATER III; KIDWELL; CAMP, 2016).

Machado (2003) argumenta que homens e mulheres se encontram na direção de empresas familiares podendo haver possíveis diferenças no modo de gestão e de representação das empresas. Dessa forma, a questão do gênero não pode ser negligenciada nos estudos de sucessão de empresas familiares.

\subsection{GÊNERO E PROCESSO SUCESSÓRIO}

Nas empresas familiares e, especialmente, no quesito sucessão, a discriminação com a parte feminina das relações é bem evidente (BARBIERI, 1997) e sofre pressões por questões como o preconceito contra a mulher que almeja estar à frente dos negócios (OVERBEKE; BILIMORIA; PERELLI, 2013), os conflitos com outros membros familiares, o equilíbrio entre vida e trabalho e a busca pelo poder.

Alguns problemas são identificados na geração herdeira, como falta de vontade em participar do negócio da família, ausência de planejamento e organização para 
direcionar os novos sucessores, dificuldades em separar os papéis familiares de suas funções no negócio, recusa das mulheres em vias de sucessão em assumir o mesmo status de trabalho perante o gênero masculino (HABERMAN; DANES, 2007).

Contudo, Machado, Wetzel e Rodrigues (2008) enfatizam que existem algumas peculiaridades em empresas em que o CEO é do gênero feminino, sendo uma delas a tendência de a segunda geração de sucessores ser constituída por mulheres.

No quesito aprendizagem, geralmente nas empresas familiares esta ocorre por meio da observação e da prática (GRZYBOVSKI, 2002; HABERMAN; DANES, 2007), ou seja, o gestor prepara seu filho (sucessor) para desenvolver formas e métodos semelhantes à sua maneira de agir. Assim, o conhecimento é transmitido de pai/ mãe para filho/filha. Quando os “permissionários” da primeira geração “[...] preparam seu sucessor; é comum que desenvolvam nesse substituto, traços de sua imagem e semelhança, socializando-o em seu mundo.” (GRZYBOVSKI, 2002, p. 131).

Autores como Lodi (1999), Overbeke, Bilimoria e Perelli (2013) e Otten-Pappas (2013) frisam que são raros os casos em que a mulher conquistou cargos diretivos em organizações geridas por homens. Geralmente isso ocorre em razão de algum infortúnio, por exemplo, morte do fundador (marido ou pai), pois enquanto ao homem se relacionam características como dedicação à carreira, objetividade e atividades desafiadoras, à mulher se destinam compromissos como maternidade e administração da casa, tarefas que podem exigir que ela trabalhe em tempo parcial ou que tenha que interromper a carreira temporária ou permanentemente (LODI, 1999).

Na mesma perspectiva, Overbeke, Bilimoria e Perelli (2013) ressaltam as diferenças entre filhos e filhas na linha de sucessão. Filhos parecem estar cientes das oportunidades nas empresas familiares, vendo-se envoltos em decisões sobre os processos de sucessão. Em contrapartida, as filhas são chamadas a ajudar no negócio da família, muitas vezes, concebendo essa ajuda como a possibilidade de "encontrar um emprego”. Em alguns casos, para as autoras, os maridos das filhas são levados para o negócio em detrimento da participação efetiva das próprias filhas.

Otten-Pappas (2013) destaca as seguintes conclusões sobre o processo sucessório envolvendo as mulheres: a sucessão relacionada ao gênero feminino ocorre quando o sucessor do sexo feminino é a primeira filha na escala de sucessão; quando a sucessão é acometida por crises/emergência; quando há custos de oportunidade envolvendo os sucessores femininos; ou quando os sucessores do sexo feminino mostram uma combinação afetivo-calculista.

A entrada de herdeiras nas empresas familiares ocorre, quase na totalidade, sem planejamento formal, direção organizacional ou identidade profissional. No en- 
tanto, geralmente, as mulheres enxergam no pai a figura do mentor, porém percebem necessitar de cautela em relação à superproteção que recebem do pai (MACHADO; WETZEL; RODRIGUES, 2008).

Vera e Dean (2005) verificaram o fato da necessidade de o pai ou fundador superproteger a filha, mais que um filho, questão que se sobrepõe à prioridade de colocá-la para lidar com problemas advindos do mundo dos negócios. Essa é uma das características do processo de sucessão pai-filha; outras dimensões do processo, além dessa, formam-se a partir da relação mãe-filha (VERA; DEAN, 2005), bem como pai-filho e mãe-filho, conforme Goffee (1996 apud MACHADO, 2003).

Na categorização pai-filho, Campos e Mazzilli (1998, p. 13) afirmam que trata-se de um processo de morte em vida, em que vê-se compelido a entregar ao filho-sucessor o sentido que conseguiu dar à sua existência e transferir-lhe a materialização do que logrou através do trabalho, enquanto patrimônio. (CAMPOS; MAZZILLI, 1998, p. 13).

Em outras palavras, parece haver mais conflitos do que concordâncias nessa relação, pois há vários questionamentos, como, por exemplo, as condições de filho, herdeiro e sucessor de alguém que possui valores, regras preconcebidas e que vêm carregadas de novos pensamentos, novas estratégias, novo formato de gestão.

Massis et al. (2016) salientam que quando um dos irmãos é visto preferencialmente pelo pai sucedido, na linha de sucessão, é comum que ambos os irmãos expressem má vontade em relação ao outro, prejudicando o relacionamento entre eles. Os autores salientam, ainda, que quanto maior a quantidade de filhos, maiores devem ser os conflitos sobre quem deve assumir a próxima geração da empresa.

Especificamente às caracterizações da configuração mãe-filha no processo sucessório, alguns pontos devem ser destacados, como facilidade de aprendizado, papel da mãe (sabedoria e força) e interdependência na relação. Contudo, Vera e Dean (2005) sugerem que as pesquisas estão em fase de construção quando da configuração mãe-filha no processo sucessório, sugerindo mais pesquisas comparativas, como pai-filho e mãe-filho. As autoras acreditam na caracterização de forma bem semelhante às duas configurações, enfatizando problemas como relutância em abrir mão do controle da gestão, falta de planejamento do processo sucessório, entre outros.

Mussolino e Calabrò (2013) confirmam que mais estudos devem ser aprofundados nas questões de gênero e processo sucessório, uma vez que os processos sucessórios pai-filho e pai-filha possuem características diferentes daqueles que envolvem mãe-filho e mãe-filha. 


\section{METODOLOGIA}

Esta é uma pesquisa de natureza aplicada, de caráter qualitativo e exploratória. Qualitativa, pois se considera que há uma relação dinâmica entre o mundo real e o sujeito que não pode ser traduzida em números (SILVA; MENEZES, 2005). Exploratória, pois busca maiores informações sobre o tema (TRIVIÑOS, 2007), bem como proporciona maior familiaridade com a situação da pesquisa, ou seja, busca explicar o problema (GIL, 2008). Para o autor, a pesquisa exploratória envolve desde o levantamento bibliográfico, lançando mão de procedimentos como, por exemplo, o estudo de caso, e pode utilizar-se de técnicas como entrevistas com sujeitos que tenham conhecimento do problema.

O estudo comparativo de casos (YIN, 2010) foi utilizado como uma estratégia para alcançar o objetivo proposto, pois possibilita o estabelecimento de comparações entre dois (ou mais) enfoques específicos, enriquecendo a pesquisa qualitativa (TRIVIÑOS, 2007). Optou-se pelo estudo comparativo de casos pelo fato de o estudo se aportar em empresas de naturezas e segmentos diferenciados, todavia, Yin (2010) defende como legítimo o estudo de casos únicos, desde que sejam representativos e que contribuam para a compreensão do fenômeno em questão.

Os dados foram coletados por meio de entrevistas em profundidade, estruturadas, em seis empresas da Cidade de Monte Carmelo, MG. Para a realização das entrevistas foi utilizado um roteiro adaptado, validado pela pesquisa de Vera e Dean (2005). Foram entrevistados sucessores de empresas familiares que passaram por pelo menos uma sucessão, contemplando as seguintes combinações de gênero: pai sucedido e filho sucessor (duas empresas); pai sucedido e filha sucessora (duas empresas); mãe sucedida e filho sucessor (uma empresa) e mãe sucedida e filha sucessora (uma empresa).

A intenção inicial era entrevistar duas empresas que se enquadrassem em cada combinação de gênero descrita no parágrafo anterior, mas não foi possível. As empresas entrevistadas foram indicadas pela Câmara de Dirigentes Lojistas (CDL) de Monte Carmelo, e nas combinações da pesquisa, segundo a Instituição, as empresas indicadas são as mais expressivas da cidade, não havendo mais empresas que apresentam as combinações mãe-filha e mãe-filho.

As entrevistas foram realizadas entre setembro de 2014 e janeiro de 2015 e tiveram o tempo médio de duração de uma hora, sendo gravadas e transcritas na íntegra, totalizando 40 páginas de transcrição.

A interpretação dos dados foi feita pela técnica de análise de conteúdo (BARDIN, 2011), pois se buscou reduzir a complexidade dos textos e falas, no senti- 
do de filtrar a classificação sistemática e a contagem de extensos volumes de texto, em uma descrição curta de características representativas do que se pretendeu descobrir (BAUER, 2002).

A técnica de interpretação dos dados da pesquisa partiu dos três polos de análise, conforme sugerido por Bardin (2011):

a) a pré-análise, em que foram identificados os indicadores/categorias de análise para a interpretação final - ressalta-se que esse ponto foi realizado a partir de roteiro adaptado, validado pela pesquisa de Vera e Dean (2005);

b) a exploração do material, em que se interpretou a transcrição das entrevistas e ocorreu a divisão dos dados em partes que tratam de:

- história da empresa;

- história do sucessor/sucessora e sua integração à empresa;

- relacionamento familiar;

- relacionamento na empresa;

- conflitos empresa-família;

- questões de sucessão e gênero;

c) tratamento dos resultados, em que se propuseram inferências e interpretações dos dados coletados.

A partir da literatura utilizada para a construção do referencial teórico, adaptando-se o roteiro de entrevistas de Vera e Dean (2005), chegou-se às seguintes categorias de análise considerando as combinações de gênero pai-filho, pai-filha, mãe-filho e mãe-filha: história da empresa; história do sucessor/sucessora e sua integração à empresa; relacionamento familiar; relacionamento na empresa; conflitos empresa-família; e questões de sucessão e gênero.

\section{ANÁLISE DOS RESULTADOS}

Os sujeitos desta pesquisa posicionam seus negócios como empresa familiar, na definição de autores (DONNELEY, 1967; GRZYBOVSKI; TEDESCO, 1998; LODI, 1998; DAVEL; COLBARI, 2000; VOZIKIS; WEAVER; GIBSON, 2009; WRIGHT; KELLERMANNS, 2011), por caracterizarem-se como empreendimentos com intenção transgeracional e, principalmente, por estarem ligados a uma família há pelo menos duas gerações. 
Todas as empresas pesquisadas são de Monte Carmelo, Minas Gerais, Município com 45.772 mil habitantes, conforme Censo Demográfico de 2010 do Instituto Brasileiro de Geografia e Estatística (IBGE), cuja renda econômica é propiciada pela agropecuária, indústria e serviços, proveniente da população economicamente ocupada -10.662 pessoas (IBGE, 2015).

Para efeito deste estudo, os sujeitos (sucessores) serão identificados como S1-P/Fo (sucessor um - categorização pai/filho); S2-P/Fo (sucessor dois pai/filho); S3-P/Fa (sucessora três - pai/filha); S4-P/Fa (sucessora quatro - pai/ filha); S5-M/Fo (sucessor quatro - mãe/filho) e S6-M/Fa (sucessora seis - mãe/ filha). Vale ressaltar a limitação deste estudo que identificou apenas uma empresa na categorização mãe/filho e uma na categorização mãe/filha.

\subsection{HISTÓRIAS DAS EMPRESAS}

As empresas pesquisadas se encontram na segunda ou na terceira gerações dos seguintes segmentos: indústria cerâmica, comércio de confecções, multiutilidades, material de construção, farmácia e serviços imobiliários. Todas as empresas já são sedimentadas (a maioria delas constituída na década de 1970) e com credibilidade no mercado da Cidade e região.

Todas tiveram seu início com pais ou mães dos sucessores e são retratadas por meio das dificuldades socioeconômicas da época, o que, segundo a totalidade dos sucessores, forçava os pais sucedidos a figurarem como o centro de apoio das famílias e as mães a complementarem a renda familiar. Tal preceito foi apontado por Machado, Wetzel e Rodrigues (2008), que ilustram as diferenças de gênero a partir de uma sociedade que exige dos homens e mulheres preceitos morais relativos aos vários papéis assumidos e presentes no corpo social dos sujeitos.

Assim, as histórias são marcadas por muito esforço e, muitas vezes, a história do fundador se confunde com a história da própria empresa. Nesse contexto, os sucessores reconhecem o valor que os sucedidos possuem e ressaltam a evolução dos negócios ainda na geração anterior, conforme Vozikis, Weaver e Gibson (2009) e Davel e Colbari (2003).

No entanto, os sucessores afirmam que fizeram alterações na gestão a partir do momento em que os sucedidos deixaram as empresas, principalmente por acreditarem que os modos de gestão tradicionalistas das gerações anteriores necessitavam de melhorias (DAVEL; COLBARI, 2003; VOZIKIS; WEAVER; GIBSON, 2009). "Meu pai sempre foi paizão, sempre tratou muito bem todas as 
pessoas, principalmente os funcionários, eu não concordava com muitas coisas que ele fazia.” (S3-P/Fa). "Não podia permitir que a empresa continuasse da forma como estava. Meu pai muito autoritário e machista e um gerente sem ética e comprometimento.” (S4-P/Fa) (informações verbais).

\subsection{HISTÓRIAS DOS SUCESSORES/SUCESSORAS E SUA INTEGRAÇÃO ÀS EMPRESAS}

Os sucessores não são filhos únicos, e alguns dividem a gestão com outros sucessores. Os filhos sucessores da combinação (pai-filho) possuem irmãos e irmãs, visto que as mulheres não foram sequer cogitadas para a possibilidade de sucessão. Em outras palavras e, por um lado, o processo sucessório, nessa combinação, era considerado certo para os filhos homens (OVERBEKE; BILIMORIA; PERELLI, 2013).

Por outro lado, na combinação mãe-filha que, apesar de caso único, a sucedida possui irmãos que também não foram sequer cogitados para o processo sucessório, como enfatizado por Machado, Wetzel e Rodrigues (2008), quando afirmam que as empresas familiares, cujos CEOs são do gênero feminino, têm a tendência de a segunda geração de sucessores ser constituída por mulheres. "Cresci vendo minha avó trabalhar, praticamente nasci na loja, foi uma coisa bem natural. Minha avó já falava: essa menina vai me substituir [...]” (S6-M/Fa) (informação verbal).

Os sucessores são casados, sujeitos de meia idade e assumiram a sucessão, primeiramente com o sucedido, quando jovens ainda (faixa etária entre 16 e 18 anos), e o processo sucessório somente foi finalizado quando os sucedidos já não possuíam mais condições físicas de continuar na gestão das empresas (LODI, 1987; SCHEFFER, 1995; FLORES JUNIOR.; GRISCI, 2012; CATER III; KIDWELL, 2013), ou em outros casos em virtude da morte do sucedido, principalmente na combinação (pai-filha), em que as duas filhas assumiram a gestão após o falecimento de seus pais (LODI, 1999; MACHADO; WETZEL; RODRIGUES, 2008; OTTEN-PAPPAS, 2013; OVERBEKE; BILIMORIA; PERELLI, 2013). “A situação, principalmente após a morte do papai, ficou muito difícil. Não que o problema tenha sido a gestão propriamente dita, mas as circunstâncias para o comércio, em cidade pequena, principalmente, é muito difícil.” (S3-P/Fa) (informação verbal).

Como os sucessores, muito jovens ainda, assumiram a gestão conjunta em tempo integral com o sucedido, a maioria não adquiriu experiência em outras empresas. Contudo, foram estimulados a buscar conhecimento teórico a fim de se prepa- 
rarem melhor para o futuro, não necessariamente no intuito de se planejarem para o processo sucessório.

Atualmente, os sucedidos assumem cargos de direção e ressaltam que a principal razão para ingressarem às empresas perpassa por um processo natural, ou seja, já dado como certo (SHARMA et al., 2001; ST-CYR; RICHER, 2005). Interessante ressaltar que essa situação não se aplica na combinação mãe-filho. Nesta, a mãe constituiu o negócio, e o filho (sucessor) integrou a empresa por necessidades pessoais e não de forma natural.

Os sucedidos enxergam mais vantagens que desvantagens em trabalhar em uma empresa familiar (HABERMAN; DANES, 2007; SILVA et al., 2013). Como vantagens, a questão mais evidente se relaciona à flexibilidade em relação aos horários do cotidiano de trabalho e à ausência de controles rígidos, como, por exemplo, o cartão de ponto. No entanto, afirmam que trabalham muito, muitas vezes sem possibilidade de programação de férias.

Mesmo nessas condições, ressaltam que não se arrependem da escolha pela empresa familiar e querem continuar na sustentabilidade das empresas, alguns já iniciando o planejamento de sucessão para a próxima geração, dessa vez, de forma mais sistematizada e com orientação profissional (LODI, 1987; CATER III; KIDWELL, 2013).

\subsection{RELACIONAMENTOS FAMILIARES}

Os entrevistados afirmam não ter havido alterações nas relações familiares com os sucedidos ou sucedidas, nem antes, nem depois do processo sucessório. Entretanto, ressaltam, conforme relatado por outros autores (SCHEFFER, 1995; CAMPOS; MAZZILLI, 1998; VOZIKIS; WEAVER; GIBSON, 2009; FLORES JUNIOR; GRISCI, 2012), a dificuldade de os sucedidos deixarem as empresas, principalmente por problemas nas gestões conjuntas, como: conflitos entre os membros; falta de planejamento para a sucessão; gosto pelos negócios; e ideia de impotência ou inutilidade.

Ela morreu trabalhando, imagina uma mulher, que em 1973 desbravava estrada para trabalhar, ganhar seu sustento e da sua família [...], se não fosse uma história, a vida da minha avó, sinceramente, preferiria fechar a empresa, mas tentei mais uma vez, contratei uma consultoria no início dos anos 2000. Fizemos um choque de gestão [...] (S6-M/Fa) (informação verbal). 
Em relação ao tempo conjunto na gestão (sucessor e sucedido), na sua maioria, o relato foi de conflitos de gerações nos formatos de trabalho ou divergência de opiniões; como afirma Lodi (1987), o processo sucessório passa por crises entre membros e períodos de tempo. “Tínhamos muita divergência, principalmente em relação ao financeiro e aos funcionários. Depois que fiquei sozinha troquei todos os funcionários, uns saíram para abrir outros negócios, outros foram demitidos, mas todos saíram.” (S3-P/Fa) (informação verbal). Em outras palavras, o sucedido com ideias tradicionalistas e o sucessor com ideias inovadoras de gestão.

Interessante ressaltar que essas considerações foram mais evidentes na combinação pai-filho/pai-filha. Nas combinações mãe-filho/mãe-filha, apesar da limitação da pesquisa - uma empresa para cada combinação - ambos os casos informaram não ter havido problemas para as mães deixarem as empresas, assim como afirmaram não ter havido conflitos em relação à gestão conjunta.

Em todas as combinações (pai-filho/pai-filha/mãe-filho/mãe-filha), os entrevistados ressaltaram não ter havido nenhum problema com mães, no caso de o pai ter sido o sucedido, e com os pais, no caso de a mãe ter sido a sucedida. Todavia, com os irmãos, estes sim apresentaram vários conflitos, revelados ou não, no momento de os sucessores assumirem os controles das empresas. De acordo com Haberman e Danes (2007) e Silva et al. (2013), os conflitos são característicos por questões acerca da herança, do ponto de vista financeiro, entre outras. No caso dos homens sucessores, estes, quando apresentaram irmãs, elas foram colocadas à parte do processo sucessório (OVERBEKE; BILIMORIA; PERELLI, 2013).

No caso dos homens sucessores que têm irmãos, por um lado, eles apenas não apresentaram conflitos quando se posicionaram em outras empresas ou em outros ramos de atuação profissional e parecem estar bem-sucedidos profissionalmente. Por outro lado, quando os irmãos atuam também nas empresas familiares, os conflitos de gestão aparecem, por vezes, evidentes e revelados, outras vezes, velados e identificados por meio de exemplos. Vale ressaltar que os conflitos se tornam contínuos, principalmente, após o processo sucessório concluído, ou seja, após a saída dos sucedidos.

No caso das mulheres sucessoras que têm irmãs, elas retratam que não possuíram interferência no processo sucessório e demonstram, na visão das sucessoras, ter se posicionado em outros segmentos de trabalho. Fato semelhante também foi observado no caso das mulheres sucessoras quando possuem irmãos, estes parecem também não ter participado do processo sucessório. “O negócio da Boutique é bem feminino, talvez por esse motivo não despertou interesse nos meus irmãos.” (S6-M/ Fa) (informação verbal). Todavia, as relações de afeto e trabalho foram afetadas. “A 
relação não é mais a mesma, meu irmão mais velho cuida da fazenda, meu irmão do meio abriu outra empresa do mesmo ramo com minha cunhada. Sem dúvida, não somos mais como éramos.” (S3-P/Fa) (informação verbal).

\subsection{RELACIONAMENTOS NAS EMPRESAS}

Todos os sucessores afirmaram não ter tido problemas com os clientes ou com os fornecedores, muito menos se sentiram discriminados por tais sujeitos. Contudo, em relação aos funcionários, alguns problemas foram observados, seja pela saída do sucedido seja por conflitos de gestão instalados de forma revelada ou não, gerando inconsistências/falhas da atual geração de gestores (LODI, 1987).

Nos casos em que o processo de sucessão, mesmo que sem planejamento sistematizado, ocorreu sem conflitos na gestão conjunta, não houveram problemas relatados com funcionários, de certa forma, contrariando a visão de Flores Junior e Grisci (2012) que afirmaram que o sucessor necessita se legitimar perante os stakeholders das empresas. Muito pelo contrário, notou-se que o processo de sucessão foi natural e os funcionários figuraram como sujeitos de apoio para o sucessor, confirmando a visão de Vozikis, Weaver e Gibson (2009) sobre as duas dimensões caracterizadas no sucesso de uma sucessão: a satisfação de todas as partes envolvidas no processo e a eficácia deste.

\subsection{CONFLITOS EMPRESA-FAMÍLIA}

Todos os sucessores afirmaram não conseguir, da forma como querem, equilibrar vida profissional e pessoal. Contudo, ressaltam que são felizes e encontram mais aspectos positivos do que negativos em sua atuação nas empresas familiares. “Minha vida é esta empresa. Não sou muito de ter vida social. Poderia fazer viagens à Europa, por exemplo, a parte financeira não é o problema. Gosto mesmo é de trabalhar, voltar para casa e cuidar dos meus animais. Gosto de descansar com eles [...]” (S4-P/Fa) (informação verbal).

Os sucessores dizem, também, que pretendem no futuro próximo tentar melhorar tal situação, contudo, parece que essa pretensão não é recente, já tentam há algum tempo. Os entrevistados ainda ressaltaram que levam para casa (dos pais - no caso dos pais vivos) assuntos referentes às empresas, com exceção da combinação mãe-filho, pois a mãe sucedida possui, atualmente, planos diferentes e incompatíveis com a empresa familiar. 


\subsection{QUESTÕES DE SUCESSÃO E GÊNERO}

Os principais problemas de sucessão relatados pelos sucessores perpassam por falta de planejamento, divergência de opiniões e conflitos entre os membros, reforçando a visão de Lodi (1987), que ilustra o processo sucessório, geralmente caracterizado por crises dessas naturezas.

Em relação à questão de gênero e à afirmação sobre o sexto oposto, todos os sucessores afirmaram que esse item não faz nenhuma diferença no processo de sucessão. Tal afirmação se torna bem evidente quando o sucessor é do sexo masculino. Quando o sucessor é do sexo feminino, a afirmação é a mesma, porém relatada de forma mais natural, sem afirmação contundente. "No início seria mais fácil caso eu fosse homem, pois as pessoas aceitariam mais, mas talvez a empresa não estaria onde está [...]” (S4-P/Fa) (informação verbal).

Importante ressaltar, por fim, que quando os sucessores homens foram questionados sobre a mudança de gênero e a aprovação de suas capacidades perante o sucedido, as respostas negativas ficaram evidentes, ou seja, se o homem fosse mulher, nada teria mudado, não precisaria ter provado mais suas capacidades simplesmente por ser mulher. Em outras palavras, para os sucessores homens parece não haver diferença entre herdeiros e herdeiras no processo sucessório, no entanto, de forma implícita nos discursos dos sucessores homens, essa diferença salta aos olhos, principalmente colocando irmãs à parte da vida organizacional e do processo sucessório.

Fato oposto ocorreu quando o questionamento se refere aos sucessores do sexo feminino. Nesse caso, as desigualdades de gênero são evidentes e o fato de não necessitarem provar suas capacidades se fossem homens, tanto para o sucedido quanto para a própria sociedade, é revelado de forma contundente em todos os discursos das combinações pesquisadas.

Por fim, é importante ressaltar que os resultados encontrados evidenciam empresas familiares de Monte Carmelo, uma Cidade de aproximadamente 50 mil habitantes. O Quadro 1 representa as características comuns dos casos estudados. 
Quadro 1 - Características comuns entre as empresas a partir das categorias de análise

\begin{tabular}{|c|c|c|c|c|}
\hline \multirow{2}{*}{ GÊNERO } & \multirow{2}{*}{ EMPRESA } & \multicolumn{3}{|c|}{ CATEGORIAS DE ANÁLISE } \\
\hline & & $\begin{array}{c}\text { História das em- } \\
\text { presas }\end{array}$ & $\begin{array}{l}\text { Sucessor(a) e sua inte- } \\
\text { gração à empresa }\end{array}$ & $\begin{array}{l}\text { Relacionamento } \\
\text { familiar }\end{array}$ \\
\hline $\begin{array}{l}\text { PAI-FI- } \\
\text { LHO }\end{array}$ & $\begin{array}{l}\mathrm{S} 1-\mathrm{P} / \mathrm{Fo} \\
\mathrm{e} \\
\mathrm{S} 2-\mathrm{P} / \mathrm{Fo}\end{array}$ & $\begin{array}{l}\text { A história do fundador } \\
\text { se confunde com a } \\
\text { empresa. Os suces- } \\
\text { sores reconhecem o } \\
\text { valor dos sucedidos e } \\
\text { ressaltam a evolução } \\
\text { dos negócios. }\end{array}$ & $\begin{array}{l}\text { O processo sucessó- } \\
\text { rio nessa combinação } \\
\text { era dado como certo } \\
\text { para os filhos ho- } \\
\text { mens. }\end{array}$ & $\begin{array}{l}\text { Problemas nas } \\
\text { gestões conjuntas: } \\
\text { conflitos entre os } \\
\text { membros; falta de } \\
\text { planejamento para } \\
\text { a sucessão; gosto } \\
\text { pelos negócios; } \\
\text { ideia de impotência } \\
\text { ou inutilidade. }\end{array}$ \\
\hline $\begin{array}{l}\text { P A I - F I - } \\
\text { LHA }\end{array}$ & $\begin{array}{l}\mathrm{S} 3-\mathrm{P} / \mathrm{Fa} \\
\mathrm{e} \\
\mathrm{S} 4-\mathrm{P} / \mathrm{Fa}\end{array}$ & $\begin{array}{l}\text { Fizeram alterações na } \\
\text { gestão depois que os } \\
\text { sucedidos deixaram as } \\
\text { empresas. }\end{array}$ & $\begin{array}{l}\text { O processo suces- } \\
\text { sório foi finalizado } \\
\text { somente quando os } \\
\text { sucedidos já não pos- } \\
\text { suíam mais condições } \\
\text { físicas de continuar } \\
\text { na gestão das empre- } \\
\text { sas. }\end{array}$ & $\begin{array}{l}\text { Conflitos de gera- } \\
\text { ções nos formatos } \\
\text { de trabalho ou diver- } \\
\text { gência de opiniões, } \\
\text { ou seja, o sucedido } \\
\text { com ideias tradicio- } \\
\text { nalistas e o sucessor } \\
\text { com ideias inovado- } \\
\text { ras de gestão. }\end{array}$ \\
\hline $\begin{array}{l}\text { M ÃE-F I - } \\
\text { LHO }\end{array}$ & S5-M/Fo & $\begin{array}{l}\text { Os sucessores reco- } \\
\text { nhecem o valor dos } \\
\text { sucedidos e ressaltam } \\
\text { a evolução dos negó- } \\
\text { cios. }\end{array}$ & $\begin{array}{l}\text { A mãe constituiu o } \\
\text { negócio, e o filho } \\
\text { (sucessor) integrou a } \\
\text { empresa por necessi- } \\
\text { dades pessoais e não } \\
\text { de forma natural. }\end{array}$ & $\begin{array}{l}\text { Não houve registro } \\
\text { de problemas para } \\
\text { as mães deixarem } \\
\text { as empresas, assim } \\
\text { como não houve } \\
\text { registro de conflitos } \\
\text { em relação à gestão } \\
\text { conjunta. }\end{array}$ \\
\hline $\begin{array}{l}\text { M Ã E- F I - } \\
\text { LHA }\end{array}$ & S6-M/Fa & $\begin{array}{l}\text { Os sucessores reco- } \\
\text { nhecem o valor dos } \\
\text { sucedidos e ressaltam } \\
\text { a evolução dos negó- } \\
\text { cios. }\end{array}$ & $\begin{array}{l}\text { Tendência de a segun- } \\
\text { da geração de suces- } \\
\text { sores ser constituída } \\
\text { por mulheres. }\end{array}$ & $\begin{array}{l}\text { Não houve registro } \\
\text { de problemas para } \\
\text { as mães deixarem } \\
\text { as empresas, assim } \\
\text { como não houve } \\
\text { registro de conflitos } \\
\text { em relação à gestão } \\
\text { conjunta. }\end{array}$ \\
\hline
\end{tabular}




\begin{tabular}{|c|c|c|c|c|}
\hline \multirow{2}{*}{ GÊNERO } & \multirow{2}{*}{ EMPRESA } & \multicolumn{3}{|c|}{ CATEGORIAS DE ANÁLISE } \\
\hline & & $\begin{array}{l}\text { História das em- } \\
\text { presas }\end{array}$ & $\begin{array}{l}\text { Sucessor(a) e sua inte- } \\
\text { gração à empresa }\end{array}$ & $\begin{array}{l}\text { Relacionamento } \\
\text { familiar }\end{array}$ \\
\hline \multirow[b]{2}{*}{ GÊNERO } & \multirow[b]{2}{*}{ EMPRESA } & \multicolumn{3}{|c|}{ CATEGORIAS DE ANÁLISE } \\
\hline & & $\begin{array}{l}\text { Relacionamento na } \\
\text { empresa }\end{array}$ & $\begin{array}{l}\text { Conflitos empresa-fa- } \\
\text { mília }\end{array}$ & $\begin{array}{l}\text { Questões de suces- } \\
\text { são e gênero }\end{array}$ \\
\hline $\begin{array}{l}\text { P A I - F I - } \\
\text { LHO }\end{array}$ & $\begin{array}{l}\mathrm{S} 1-\mathrm{P} / \mathrm{Fo} \\
\mathrm{e} \\
\mathrm{S} 2-\mathrm{P} / \mathrm{Fo}\end{array}$ & $\begin{array}{l}\text { Os funcionários foram } \\
\text { sujeitos de apoio para } \\
\text { o sucessor. }\end{array}$ & $\begin{array}{l}\text { Há registros de mais } \\
\text { aspectos positivos } \\
\text { do que negativos na } \\
\text { atuação dos sucesso- } \\
\text { res. }\end{array}$ & $\begin{array}{l}\text { Quando o sucedido } \\
\text { é do sexo masculino } \\
\text { a gestão parece ser } \\
\text { mais centralizadora } \\
\text { e tradicionalista. }\end{array}$ \\
\hline $\begin{array}{l}\text { P A I - F I - } \\
\text { LHA }\end{array}$ & $\begin{array}{l}\mathrm{S} 3-\mathrm{P} / \mathrm{Fa} \\
\mathrm{e} \\
\mathrm{S} 4-\mathrm{P} / \mathrm{Fa}\end{array}$ & $\begin{array}{l}\text { Os funcionários foram } \\
\text { sujeitos de apoio para } \\
\text { o sucessor. }\end{array}$ & $\begin{array}{l}\text { Há registros de mais } \\
\text { aspectos positivos } \\
\text { do que negativos na } \\
\text { atuação dos sucesso- } \\
\text { res. }\end{array}$ & $\begin{array}{l}\text { Para as sucessoras, } \\
\text { houve a necessidade } \\
\text { de provar as capaci- } \\
\text { dades empresariais, } \\
\text { tanto para os sucedi- } \\
\text { dos (homens) quan- } \\
\text { to para a sociedade } \\
\text { em geral, fato que } \\
\text { para elas não ocor- } \\
\text { reria caso fossem do } \\
\text { sexo masculino. }\end{array}$ \\
\hline $\begin{array}{l}\text { MÃ E-FI- } \\
\text { LHO }\end{array}$ & S5-M/Fo & $\begin{array}{l}\text { Os funcionários foram } \\
\text { sujeitos de apoio para } \\
\text { o sucessor. }\end{array}$ & $\begin{array}{l}\text { Há registros de mais } \\
\text { aspectos positivos } \\
\text { do que negativos na } \\
\text { atuação dos sucesso- } \\
\text { res. }\end{array}$ & $\begin{array}{l}\text { Quando o sucedido } \\
\text { é do sexo masculino } \\
\text { a gestão parece ser } \\
\text { mais centralizadora } \\
\text { e tradicionalista. }\end{array}$ \\
\hline
\end{tabular}




\begin{tabular}{|c|c|c|c|c|}
\hline \multirow{2}{*}{ GÊNERO } & \multirow{2}{*}{ EMPRESA } & \multicolumn{3}{|c|}{ CATEGORIAS DE ANÁLISE } \\
\hline & & $\begin{array}{l}\text { História das em- } \\
\text { presas }\end{array}$ & \begin{tabular}{|c|}
$\begin{array}{c}\text { Sucessor(a) e sua inte- } \\
\text { gração à empresa }\end{array}$ \\
\end{tabular} & $\begin{array}{l}\text { Relacionamento } \\
\text { familiar }\end{array}$ \\
\hline $\begin{array}{l}\text { MÃE-FI- } \\
\text { LHA }\end{array}$ & S6-M/Fa & $\begin{array}{l}\text { Os funcionários foram } \\
\text { sujeitos de apoio para } \\
\text { o sucessor. }\end{array}$ & $\begin{array}{l}\text { Há registros de mais } \\
\text { aspectos positivos } \\
\text { do que negativos na } \\
\text { atuação dos sucesso- } \\
\text { res. }\end{array}$ & $\begin{array}{l}\text { Quando o sucedido } \\
\text { é do sexo femini- } \\
\text { no, parece que as } \\
\text { preocupações não } \\
\text { se concentram so- } \\
\text { mente no processo } \\
\text { sucessório, mas em } \\
\text { outros contextos da } \\
\text { vida cotidiana das } \\
\text { relações. }\end{array}$ \\
\hline
\end{tabular}

\section{CONCLUSÃO}

O processo de sucessão em empresas familiares é um dos temas mais recorrentes e estudados na academia. Apesar disso, não há um consenso sobre a maneira mais eficaz de gerenciar esse processo nas organizações, dadas as particularidades existentes fruto da relação empresa, propriedade e família. Como forma de contribuir para as discussões, neste trabalho teve-se como objetivo analisar os desafios enfrentados por sucessores no processo de sucessão em empresas familiares, considerando diferentes combinações de gênero.

Nas empresas participantes deste trabalho, as trajetórias se interligam no início de suas atividades, caracterizadas pelas dificuldades socioeconômicas da época, em que os pais sucedidos figuravam como o centro de apoio das famílias e as mães complementavam a renda familiar, auxiliando perifericamente seus companheiros, em casa ou na própria empresa, ou em ambos os espaços.

Todos os sucessores reconhecem o valor dos sucedidos como fundadores das organizações e ressaltam que houve a evolução dos negócios, no entanto, nas várias combinações de gênero pesquisadas, os sucessores afirmam que fizeram alterações na gestão a partir do momento em que os sucedidos deixaram as empresas, principalmente por acreditarem que os modos de gestão tradicionalistas das gerações anteriores necessitavam de melhorias.

Em relação ao sexo oposto no processo sucessório, todos os sucessores afirmaram que essa é uma questão que não faz diferença em termos de gestão na empresa 
familiar. No entanto, tal afirmação é mais contundente quando o sucessor é do sexo masculino, não sendo tão evidenciada para o sexo feminino. Em outras palavras, para os sucessores do sexo masculino, parece não haver diferenças entre homens e mulheres no processo sucessório. Todavia, de forma implícita nos discursos dos sucessores homens, essa diferença salta aos olhos, principalmente colocando irmãs à parte da vida organizacional e do processo sucessório.

Para as mulheres sucessoras, essa diferença é mostrada, principalmente, na necessidade de provar suas capacidades empresariais, tanto para os sucedidos (homens) quanto para a sociedade em geral, fato que, para elas, não ocorreria caso fossem do sexo masculino.

Em relação aos sucedidos, pode-se perceber que há diferenças entre as combinações de gênero pai-filho/pai-filha e mãe-filho/mãe-filha, principalmente em se tratando de sucedidos homens e mulheres. Quando o sucedido é do sexo masculino, a gestão parece ser mais centralizadora e tradicionalista com este figurando à frente dos negócios. Quando o sucedido é do sexo feminino, parece que as preocupações não se concentram somente no processo sucessório, mas em outros contextos da vida cotidiana das relações.

Interessante ressaltar que, em alguns casos, a sucessão era dada como certa para os filhos homens; quando da combinação mãe-filha, não se cogitou a possibilidade dos irmãos para o processo sucessório. Em todas as combinações de gênero, não há arrependimentos da escolha pela empresa familiar; há, ainda, a evidência da importância na continuidade e na sustentabilidade das organizações, algumas já iniciando o planejamento de sucessão para a próxima geração, todavia, de forma mais sistematizada e com orientação profissional.

No momento em que os sucessores efetivamente assumiram a gestão das empresas, os conflitos com os irmãos se evidenciaram, estes ilustrados de forma revelada ou não. Entre os fatores de conflitos, pode-se ressaltar questões acerca da herança e divergências do ponto de vista financeiro em relação à gestão do sucessor. Nesse sentido, e por consequência, as relações de afeto e trabalho foram afetadas. Nos casos em que a sucessão ocorreu a partir de planejamento sistematizado, notou-se que o processo foi natural e houve apoio ao sucessor, principalmente por parte dos funcionários.

Partindo dos pressupostos interrogativos deixados pelo trabalho, algumas sugestões de estudos futuros se pautam, como, por exemplo, o aprofundamento das combinações de gênero e processos sucessórios em empresas de outros municípios com características iguais as encontradas em Monte Carmelo, MG, a fim 
de aprofundar e confirmar os resultados. Outra sugestão seria tratar empresas familiares e seus respectivos processos sucessórios, considerando municípios com características diferentes das encontradas em Monte Carmelo, MG, realizando estudos de caso comparativos.

\section{REFERÊNCIAS}

BARBIERI, E. M. A batalha das herdeiras na empresa familiar. Porto Alegre: Sagra, 1997.

BARDIN, L. Análise de Conteúdo. São Paulo: Edições 70, 2011.

BAUER, M. W. Análise de conteúdo clássica: uma revisão. In: BAUER, M. W.; GASKELL, G. (Ed.). Pesquisa qualitativa com texto, imagem e som: um manual prático. Petrópolis: Vozes, 2002.

CAMPOS, L. J.; MAZZILLI, C. Análise do processo sucessório em empresa familiar: um estudo de caso. In: ENCONTRO DA ASSOCIAÇÃO NACIONAL DE PÓS-GRADUAÇÃO EM ADMINISTRAÇÃO, 22., 1998, Rio de Janeiro. Anais... Rio de Janeiro: Anpad, 1998. CD-ROM.

CATER III, J. J.; KIDWELL, R. E.; CAMP, K. M. Successor Team Dynamics in Family Firms. Family Business Review, v. 29, i. 3, p. 301-326, 2016.

CATER III., J. J.; KIDWELL, R. E. Function, governance, and trust in successor leadership groups in family firms. Journal of Family Business Strategy, p. 12, 2013. Disponível em: <http:/ /dx.doi.org/10.1016/j.jfbs.2013.06.001>. Acesso em: 08 ago. 2014.

CONSOLI, M. A.; MARTINELLI, D. P. Administração de Empresas Familiares. In: SEMINÁRIOS DE ADMINISTRAÇÃO, 3., 1998, São Paulo. Anais... São Paulo: FEA: USP, 1998.

DAVEL, E.; COLBARI, A. Organizações familiares: desafios, provocações e contribuições para a pesquisa organizacional. In: ENCONTRO DA ASSOCIAÇÃO NACIONAL DE PÓS-GRADUAÇÃO EM ADMINISTRAÇÃO, 27., 2003, Atibaia. Anais... Rio de Janeiro: Anpad, 2003. CD-ROM.

DAVEL, E.; COLBARI, A. Organizações familiares: por uma introdução a sua tradição, contemporaneidade e multidisciplinaridade. Revista Organizações \& Sociedade, Salvador, v. 7, n. 18, p. 45-64. 2000. 
DONNELEY, R. G. A empresa familiar. Revista de Administração de Empresas, São Paulo, v. 7, n. 23, p. 161-198, abr./jun. 1967.

FLORES JUNIOR, J. E.; GRISCI, C. L. T. Dilemas de pais e filhos no processo sucessório de empresas familiares. R. Adm., São Paulo, v. 47, n. 2, p. 325-337, abr./ maio/jun. 2012.

GERSICK, K. E. et al. De Geração para Geração: ciclos de vida das empresas familiares. 4. ed. Rio de Janeiro: Negócio, 1997.

GIL, A. C. Como elaborar projetos de pesquisa. 4. ed. São Paulo: Atlas, 2008.

GRZYBOVSKI, D. O administrador na empresa familiar: uma abordagem comportamental. Passo Fundo: UPF, 2002.

GRZYBOVSKI, D.; TEDESCO, J. C. Empresa familiar X competitividade: tendências e racionalidades em conflito. Revista Teoria e Evidência Econômica, Passo Fundo, v. 6, n. 11, p. 37-68, nov. 1998.

HABERMAN, H.; DANES, S. M. Father-daughter and father-son family business management transfer comparison: family FIRO model application. Family Business Review, Thousand Oaks, v. 20, n. 2, p. 163-184, 2007.

IBGE. Cidades @. Disponível em: <http://www.cidades.ibge.gov.br/xtras/perfil. php?lang=\&codmun=314310\&search=minas-gerais|monte-carmelo|infograficos:-informacoes-completas>. Acesso em: 25 abr. 2015.

LODI, J. B. A empresa familiar. 5. ed. São Paulo: Pioneira, 1998.

LODI, J. B. Fusões e aquisições: o cenário brasileiro. Rio de Janeiro: Campus, 1999.

LODI, J. B. Sucessão e conflito na empresa familiar. São Paulo: Pioneira, 1987.

MACEDO, K. B. et al. A Exclusão da Mulher No Processo De Sucessão Familiar. In: ENCONTRO DE ESTUDOS ORGANIZACIONAIS, 3., 2004, São Paulo. Anais... São Paulo: Anpad, 2004. CD-ROM.

MACHADO, H. V. Sucessão familiar e gênero: implicações para estudos sobre empresas familiares. In: EGEPE - ENCONTRO DE ESTUDOS SOBRE EMPREENDEDORISMO E GESTÃO DE PEQUENAS EMPRESAS. 3. 2003, Brasília. Anais... Brasília: UEM/UEL/UnB, 2003, p. 562-573. 
MACHADO, R. M. C.; WETZEL, U.; RODRIGUES, M. E. A experiência de sucessão para herdeiras de empresas familiares do Rio de Janeiro. Cadernos EBAPE.BR, v. 6, n. 3, set. 2008. Disponível em: <http://bibliotecadigital.fgv.br/ojs/ index.php/cadernosebape/article/viewFile/5086/3820>. Acesso em: 03 nov. 2014.

MASSIS, A. et al. Incumbent's Attitude Toward Intrafamily Succession: an Investigation of Its Antecedents. Family Business Review, v. 29, n. 3, p. 278-300, 2016.

MUSSOLINO, D.; CALABRÒ, A. Paternalistic leadership in family firms: Types and implications for intergenerational succession. Journal of Family Business Strategy, 2013. Disponível em: <http://dx.doi.org/10.1016/j.jfbs.2013.09.003>. Acesso em: 10 abr. 2014.

OTTEN-PAPPAS, D. I. M. The female perspective on family business successor commitment. Journal of Family Business Management, v. 1, i. 3, p. 8-23, 2013.

OVERBEKE, K. K.; BILIMORIA; D.; PERELLI, S. The dearth of daughter successors in family businesses: Gendered norms, blindness to possibility, and invisibility. Journal of Family Business Strategy, i. 4, p. 201-212, 2013.

SCHEFFER, A. B. B. Fatores dificultantes e facilitadores ao processo de sucessão familiar. Revista de Administração, São Paulo, v. 30, p. 80-90, 1995.

SHARMA, P. et al. Determinants of initial satisfaction with the succession process in family firms: A conceptual model. Entrepreneurship: Theory and Practice, v. 25, i. 3, p. 17-35. 2001.

SILVA, E. L.; MENEZES, E. M. Metodologia da Pesquisa e Elaboração de Dissertação. 4. ed. rev. Florianópolis: UFSC, 2005.

SILVA, R. G. et. al. Conatus e o processo sucessório: limites e possibilidades à continuidade da empresa familiar. In: ENCONTRO DA ASSOCIAÇÃO NACIONAL DE PÓS-GRADUAÇÃO EM ADMINISTRAÇÃO, 37., 2013, Rio de Janeiro. Anais... Rio de Janeiro: Anpad, 2013. CD-ROM.

SIMON, A. et al. Exploring value differences across family firms: The influence of choosing and managing complexity. Journal of Family Business Strategy, i. 3, p. 132-146, 2012.

STAMM, I.; LUBINSKI, C. Crossroads of family business research and firm demography: A critical assessment of family business survival rates. Journal of Family Business Strategy, i. 2, p. 117-127, 2011. 
ST-CYR, L.; RICHER, F. La planification du processus de transmission dans les PME québécoises. Revue Internationale P.M.E., v. 18, n. 3-4, 2005.

TRIVIÑOS, A. N. S. Introdução à Pesquisa em Ciências Sociais: a pesquisa qualitativa em educação. São Paulo: Atlas, 2007.

VERA, C. F.; DEAN, M. A. An Examination of the Challenges Daughters face in Family Business Succession. Family Business Review, v. 23, i. 4, p. 321-345, Dec. 2005.

VOZIKIS, G. S.; WEAVER, K. M.; GIBSON, B. Family business succession: emphasis on the family not the business. Indian Journal of Economics \& Business, p. 139-153, 2009. Special Issue.

WRIGHT A. M.; KELLERMANNS, F. W. Family firms: A research agenda and publication guide. Journal of Family Business Strategy, i. 2, p. 187-198, 2011.

YIN, R. K. Estudo de caso: planejamento e métodos. 4. ed. Porto Alegre: Bookman, 2010.

\section{Como citar este artigo:}

ABNT

VASCONCELOS, Andrea Costa van Herk; OLIVEIRA, Márcia Freire de; FERNANDES, Vivian Duarte Couto. O processo de sucessão em diferentes combinações de gênero: um estudo comparativo de casos em empresas familiares de Monte Carmelo, MG. RACE, Revista de Administração, Contabilidade e Economia, Joaçaba: Ed. Unoesc, v. 16, n. 1, p. 203-226, jan./abr. 2017. Disponível em: <http:// editora.unoesc.edu.br/index.php/race>. Acesso em: dia/mês/ano.

APA

Vasconcelos, A. C. van H., Oliveira, M. F. de, \& Fernandes, V. D. C. (2017). O processo de sucessão em diferentes combinações de gênero: um estudo comparativo de casos em empresas familiares de Monte Carmelo, MG. RACE, Revista de Administração, Contabilidade e Economia, 16(1), 203-226. Recuperado em dia/mês/ano, de http://editora.unoesc.edu.br/index.php/race 